\title{
Imprinting: Effects of drug induced immobilization'
}

\author{
GLENN E. MACDONALD AND A. SOLANDT \\ UNIVERSITY OF TORONTO
}

The imprinting test performance of a group of newly hatched domestic chicks which had been immobilized with Flaxedil during exposure to an imprinting stimulus was compared to that of a group which had been exposed without drug. The performance of the Flaxedil group was significantly lower than that of the regularly imprinted group and, in fact, did not differ from that of two control groups which had no previous imprinting experience. This finding suggests that some form of response is necessary for the occurrence of imprinting.

It has been maintained by Hess (1959) that imprinting is a function of the effort expended in the execution of the following or approach response. Sluckin (1964) has recently reviewed confinement studies designed to test Hess' hypothesis and concludes that the majority of these seem to indicate that following or approach responses are not necessary for imprinting to occur. While these studies dealt exclusively with the birds' overt locomotor behavior, the implication has been that no effort or response of any kind is necessary for imprinting.

The present authors suggest, however, that confinement studies are not a good test for the role of effort in the establishment of imprinting behavior. Confinement does not prevent activity or effort but merely limits the kind and direction of such activity.

It is argued therefore that imprinting involves more than sensory input. In fact, it may be that a particular stimulus acquires imprinting value only insofar as the behavior involved transforms sensory input from it.

The purpose of this experiment was to test this hypothesis by blocking overt motor responses in newly hatched chicks using the muscle relaxant gallamine triethiodide (Flaxedil) during exposure to the imprinting stimulus and subsequently testing for approach behavior under a no drug condition.

Method

Subjects. The Ss in this experiment were 36 White Rock Cornish chicks. The chicks were incubated in the laboratory and were between 12 and $20 \mathrm{hr}$. old when first exposed to the experimental conditions.

Apparatus. The imprinting apparatus was similar to that described by James (1959). It consisted of a wooden alley $6 \mathrm{ft}$. $x 1 \mathrm{ft} . x 1 \mathrm{ft}$. painted flat black. At each end of the alley there was a source of intermittent light and sound. The light was provided through four holes $3 / 4$ in. in diameter arranged in a diamond pattern on 4 in. centers. The light flickered at the rate of $.5 \mathrm{sec}$. on and .5 sec. off. The intermittent sound was provided by a small PM speaker from a solid state metronome module and it also had a $.5 \mathrm{sec}$. on/off rate.

Design and Procedure. The Ss in this experiment were divided into four groups of nine birds each. On the day of hatching and on the following two days these groups received differential treatment. The birds in Group I were injected with water and subjected to an imprinting procedure. The Ss in Group FI were injected with Flaxedil and then placed in the imprinting situation. The Ss in Group CI were injected with water and placed in the imprinting apparatus in the absence of the imprinting stimuli. The Ss in Group CO were injected with water and returned to their living compartments in a forced air brooder. Following these procechures all groups were tested in the standard imprinting situation on days 4 and 5 after hatching.

The imprinting procedure consisted of placing the bird in the alley with the stimulus, consisting of intermittent light and sound, on at one end. When the bird had approached within $12 \mathrm{in}$. of that stimulus and when $60 \mathrm{sec}$. had elapsed the stimulus was switched off at that end and switched on at the other end. These 60 sec. trials were repeated five times each day resulting in a procedure functionally equivalent to following. The atimulus switching procedure was subject to the restriction that it would not be switched to the opposite end if such a switch brought it closer to the bird. In that case it remained where it had been for a further $60 \mathrm{sec}$. period. The bird's imprinting score was the total time spent within 12 in. of the stimulus during the $5 \mathrm{~min}$. exposure.

The drug immobilized group FI received $1.5 \mathrm{mg} / \mathrm{kg}$ of Flaxedil injected interperitoneally $15 \mathrm{~min}$. before being placed in the imprinting apparatus. It had been determined in pilot work that this dosage of drug resulted in total immobilization of the bird and acceptably low death rates. The three control groups received equivalent injections of sterile water.

Results

The mean time spent within 12 in. of the stimulus on the day 4 and day 5 test trials are shown in Table 1 . It can be seen that the regularly imprinted group, Group I, have very much larger scores than all other groups. The Flaxedil group does, however, have slightly higher scores on both days than either CI or CO. These differences were tested with analysis of variance and it was found that the only significant difference was between

Table 1. Mean time spent within 12 in. of the imprinting stimulus on test days

\begin{tabular}{lcc} 
Group & Time spent within 12 in. in seconds \\
\hline & Test day I & Test day 2 \\
\cline { 2 - 3 } I - imprinted & 152.3 & 151.9 \\
FI - Flaxedil imprinted & 43.2 & 74.1 \\
CI - Control - alley & 25.3 & 58.4 \\
CO - Control - home cage & 30.3 & 50.1 \\
\hline
\end{tabular}


groups $(F=3.46$, df $=3 / 32, p<.05)$. A subsequent analysis using Duncan's Multiple Range test revealed that Group I was significantly different from all other groups. Group FI was not significantly different from the two control groups.

\section{Discussion}

The major finding of this experiment was that birds immobilized with Flaxedil and exposed to an Imprinting stimulus do not approach that stimulus on subsequent tests any better than birds that have never been exposed at all. This result does not directly confirm Hess' law of effort but it does suggest that some form of response is necessary for imprinting procedures to be effective.

Since Flaxedil is reported to leave the sensorium relatively intact, the present results would strongly suggest that the role of responses in imprinting are worthy of further investigation. From the results of this experiment and the observations of Moltz et al (1960) and of Collins (1965) that confined birds in the imprinting situa- tion shows little overt gross behavior, it would appear that the responses necessary for imprinting to occur are relatively fine responses such as those involved in perception.

\section{References}

Collins, Thomas B., Jr. Strength of the following response in the chick in relation to degree of "parent" contact. J. comp. physiol. Psychol, 1965, 60, 192-195.

Hess, E. H. Imprinting. Science, 1959, 130, 133-141.

James, H. Flicker: An unconditioned stimulus for imprinting. Canad. J. Psychol., 1959, 12, 59-67.

Moltz, H., Rosenblum, L., \& Stettner, L. J. Some parameters of imprinting effectiveness. J. comp. physiol. Psychol., 1960, 53, 297-301.

Sluckin, W. Imprinting and early learning. London: Methuen, 1964. Note

1. This study was supported by grants from the National Research Council (APT-116) and the Alcoholism and Drug Addiction Foundation of Ontario. 